\title{
Cross-Talk das Vias de Sinalização de Insulina e Angiotensina II: Implicações Com a Associação Entre Diabetes Mellitus e Hipertensão Arterial e Doença Cardiovascular
}

\begin{abstract}
RESUMO
Insulina (Ins) e Angiotensina II (AII) são fundamentais no controle de dois sistemas vitais e inter-relacionados: o metabólico e o cardiocirculatório, respectivamente. A disfunção de qualquer um desses hormônios pode levar ao desenvolvimento de duas doenças de alta prevalência, muitas vezes concomitantes e, talvez, com fisiopatologia integrada - diabetes mellitus (DM) e hipertensão arterial (HA). Vários estudos mostram que os sistemas de sinalização intracelular de Ins e All estão conectados e influenciam um ao outro. Esta comunicação molecular ocorre em diferentes etapas da sinalização celular e é importante para vários fenômenos fisiológicos, desde o desenvolvimento de hipertrofia cardíaca e aquisição de energia pelo coração, até a ação de drogas anti-hipertensivas. No nível extracelular, a enzima de conversão de angiotensina regula a síntese de All e o acúmulo de bradicinina, e ambos desempenham papel regulador sobre a sinalização de Ins. No nível intracelular, a interação dos sinais de Ins e All ocorre em dois momentos distintos. Inicialmente, em etapas mais precoces da sinalização celular, a All, atuando através da cascata JAK-2/IRS-1/PI3-quinase, JNK e ERK, provoca a fosforilação em serina e a conseqüente inibição de elementos-chave da via de sinalização da Ins. Finalmente, a All induz a expressão da proteína regulatória SOCS-3, que impõe um controle mais tardio sobre o sinal de Ins. Esta revisão discute os avanços mais recentes neste campo e a importância dessa interação molecular na fisiopatologia e na associação clínica de DM e HA. (Arq Bras Endocrinol Metab 2007;51/2:195-203)
\end{abstract}

Descritores: Insulina; Angiotensina II; Doença cardiovascular; Hipertensão arterial

\section{ABSTRACT}

Insulin and Angiotensin II Signaling Pathways Cross-Talk: Implications with the Association Between Diabetes Mellitus, Arterial Hypertension and Cardiovascular Disease.

Insulin (Ins) and angiotensin II (AII) play pivotal roles in the control of two vital and closely related systems: the metabolic and the circulatory, respectively. A failure in the proper action of each of these hormones results, to a variable degree, in the development of two highly prevalent and commonly overlapping diseases - diabetes mellitus (DM) and hypertension ( $\mathrm{AH}$ ). In recent years, a series of studies has revealed a tight connection between the signal transduction pathways that mediate Ins and All actions in target tissues. This molecular cross-talk occurs at multiple levels and plays an important role in phenomena that range from the action of anti-hypertensive drugs to cardiac hypertrophy and energy acquisition by the heart. At the extracellular level, the angiotensin-converting enzyme controls All synthesis but also interferes with Ins signaling through the proper regulation of All and the accumulation of bradykinin. At an early intracellular level, All, acting through JAK-2/IRS-1/PI3kinase, JNK and ERK, may induce the serine phosphorylation and inhibition of key elements of the Ins-signaling pathway. Finally, by inducing the expression of the regulatory protein SOCS-3, All may impose a late control on the Ins signal. This review will focus on the main advances obtained in this field and will discuss the implications of this molecular cross-talk in the common clinical association between DM and AH. (Arq Bras Endocrinol Metab 2007;51/2:195-203)

Keywords: Insulin; Angiotensin II; Cardiovascular disease; Arterial hypertension; Cardiovascular disease atualização

\author{
Marco A. de Carvalho-Filho \\ José Barreto C. Carvalheira \\ Lício augusto VelLoso \\ Mario José AbDalla SAAD
}

Departamento de Clínica

Médica, Faculdade de Ciências

Médicas da Universidade

Estadual de Campinas, SP.
Recebido em: 37/12/06

Aceito em: 05/01/07 
A ESISTÊNCIA À INSULINA É DEFINIDA como uma resposta biológica sub-normal a uma determinada concentração deste hormônio. Cada vez mais prevalente em nossa sociedade, ela acompanha várias situações clínicas, como a obesidade, o diabetes mellitus tipo 2, a hipertensão arterial, processos infecciosos, algumas doenças endócrinas e a síndrome do ovário policístico (1-4). Esta resistência hormonal tem despertado grande atenção, tanto na pesquisa clínica, quanto na básica, em função de sua associação com a doença cardiovascular $(5,6)$. No entanto, os mecanismos moleculares que ligam a resistência à insulina à hipertensão arterial, à hipertrofia cardíaca, e ao desenvolvimento e progressão da aterosclerose, ainda não são completamente conhecidos, apesar dos progressos alcançados nas últimas décadas $(5,7)$.

$\mathrm{Na}$ grande maioria das vezes, o termo resistência à insulina é empregado tendo-se como referência o controle glicêmico, refletindo um efeito inadequado da insulina na homeostase da glicose. No entanto, a insulina tem ações pleiotrópicas, modulando diversas funções celulares, como por exemplo o metabolismo de lipídeos e proteínas, o transporte de íons e aminoácidos, a proliferação e o ciclo celular, a diferenciação celular, apoptose e a síntese de óxido nítrico (NO) $(1,8,9)$. Assim, quando consideramos situações de resistência à insulina, não devemos levar em conta apenas o metabolismo de glicose, mas sim toda a gama de ações metabólicas e de crescimento da insulina. Devemos considerar, também, que a resistência à insulina pode afetar essas funções de forma heterogênea (5).

Na maioria das situações de redução da sensibilidade à insulina, observamos uma hiperinsulinemia compensatória. Entendemos hoje que o aparecimento de resistência à insulina não é uniforme em relação aos tecidos-alvo desse hormônio, nem em relação às vias intracelulares ativadas pela insulina. Desta forma, ao mesmo tempo em que a resistência à insulina pode afetar negativamente certas funções metabólicas desse hormônio, a hiperinsulinemia compensatória pode intensificar outras. Além do mais, a interação entre a insulina e outros hormônios, tais como a angiotensina II (ang II), a adrenalina, o hormônio do crescimento e a leptina, entre outros, pode modular os efeitos finais da ação insulínica.

Dentre os diversos hormônios cujas vias de sinalização intracelular interagem com as vias de sinalização insulínica, a angiotensina II tem despertado grande interesse devido à significativa associação clínica entre diabetes mellitus tipo 2 (DM2) e hipertensão arterial. A associação entre estas duas doenças é conhecida há muito tempo, mas o aumento da incidên- cia de aterosclerose, acompanhada do aumento da mortalidade cardiovascular, que tem nessas enfermidades seus principais fatores de risco, tem reforçado nosso interesse no entendimento desta associação. Além disso, a atual epidemia de obesidade, sabidamente associada à resistência à insulina e ao desenvolvimento de DM2 e hipertensão arterial, lança novos desafios neste sentido (10).

$\mathrm{Na}$ última década, vários grupos de pesquisadores, incluindo o nosso, buscaram entender como os sistemas de sinalização celular de insulina e angiotensina se relacionam, e alguns avanços foram feitos, mostrando que esta interação ocorre em diferentes níveis de sinalização celular, através de proteínas celulares diferentes. Esta interação modula as diversas funções celulares da insulina de uma forma diversificada, afetando funções celulares diferentes.

\section{O SISTEMA DE SINALIZAÇÃO DA ANGIOTENSINA II}

A maioria das ações conhecidas da angiotensina II é desencadeada pela sua ligação ao seu receptor de membrana $A T 1$, um receptor associado à proteína $G$, que estimula a fosfolipase C (11). A fosfolipase $\mathrm{C}$ beta, uma vez ativada, induz a formação de trifosfato de inositol, assim como de diacilglicerol, o que provoca a liberação e aumento da concentração citoplasmática de $\mathrm{Ca}^{++}$, levando à ativação da proteína quinase $\mathrm{C}$ e da adenil-ciclase regulada pelo receptor ATl (12). Além de ativar a via de sinalização associada à proteína $G$, a ligação da angiotensina II ao seu receptor ATl é capaz de induzir uma cascata de ativação via tirosinas-quinases $(13,14)$. Uma série de tirosinas-quinases pode ser ativada a partir da ativação do ATl, desde tipos nãoreceptores [Src, Fyn, Yes, Pyk2, FAK, e Janus kinase 2 (JAK2)] até tipos receptores (receptores de EGF e PDGF). Essas tirosinas-quinases regulam vias efetoras intracelulares, incluindo a PLC-gama, Ras-Raf-MAPK quinase (MEK)-ERK, e signal transducers and activator of transcription (STATs) (15). Muitas dessas proteínas atuam como pontos de convergência de diferentes cascatas de sinalização induzidas por diferentes hormônios, fatores de crescimento e citocinas, representando, portanto, importantes pontos de interação molecular na sinalização intracelular destas substâncias (figura 1).

Além do receptor AT1, a angiotensina II pode também se ligar e ativar outro receptor conhecido como AT2. Apesar desse receptor ter a estrutura transmembrana clássica de um receptor associado à proteína $G$, ele parece exercer seus efeitos intracelulares de 


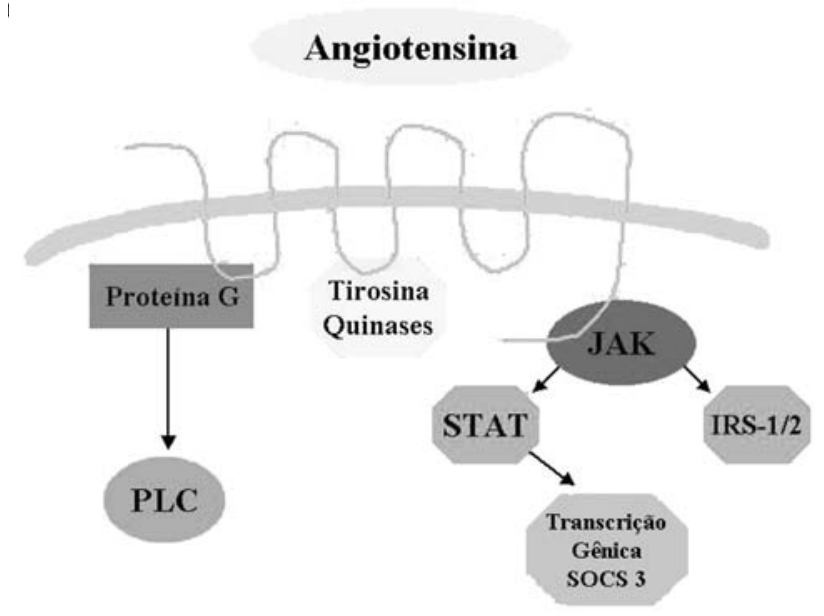

Figura 1. Via de sinalização da angiotensina.

forma distinta $(16,17)$. Na verdade, a cascata de sinalização desencadeada pelo AT2 ainda é motivo de controvérsia. A maioria dos estudos mostra que o AT2 é capaz de ativar a fosfatase de serina/treonina PP2A, que direciona o sinal para o controle da atividade de canais de $\mathrm{K}^{+}$e $\mathrm{Ca}^{++}(17,18)$. Além disso, alguns estudos mostram que a ativação do AT2 regula negativamente a ativação da cascata MAP quinase desencadeada pela ativação do ATl (19). Finalmente, foi descrita também a capacidade do AT2 em ativar a $\mathrm{PLA}_{2}(20)$.

\section{O SISTEMA DE SINALIZAÇÃO DA INSULINA}

O receptor de insulina pertence à família dos receptores de membrana que possuem capacidade tirosinaquinase intrínseca. Ele é composto de duas subunidades $\alpha$ extra-celulares e duas sub-unidades $\beta$ transmembrana, ligadas por ponte dissulfeto (9). A insulina liga-se à sub-unidade $\alpha$ do receptor, provocando uma mudança conformacional na sub-unidade $\beta$, que leva a sua auto-fosforilação em tirosina e ativa sua capacidade tirosina-quinase. Uma vez ativado, o receptor de insulina é capaz de fosforilar diversos substratos intracelulares, entre eles os substratos do receptor de insulina (IRS-1-4), Shc (Src homology collagen) e JAK-2 $(9,21,22)$. Essas proteínas, uma vez fosforiladas, recrutam e ativam diversos efetores intracelulares, com diversas funções celulares diferentes (9). A via da ERK está principalmente envolvida no controle do crescimento e da mitogênese, enquanto a ativação da PI-3 quinase pelo IRS-1 está preferencialmente ligada às ações metabólicas da insulina $(9,23)$ (figura 2).

Recentemente, demonstrou-se que a regulação da sinalização de insulina pode estar associada a um

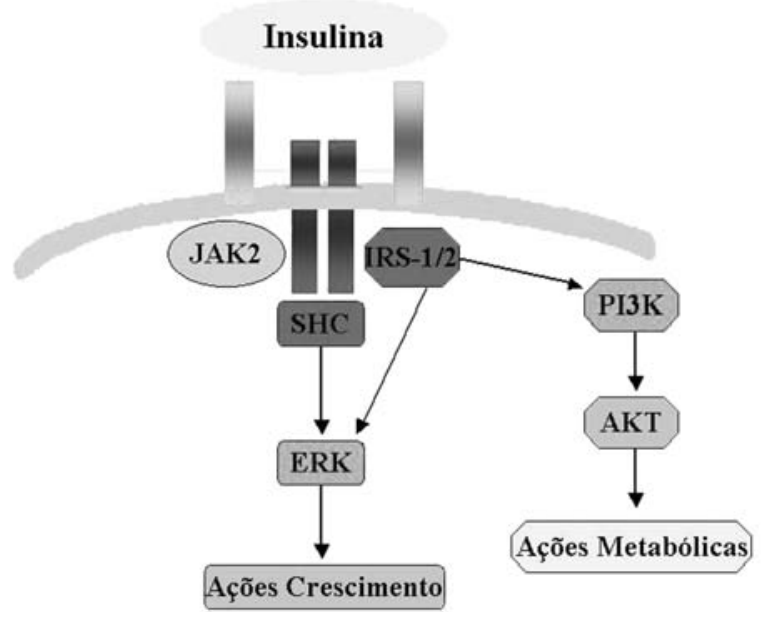

Figura 2. Via de sinalização da insulina.

balanço entre a modulação positiva que acontece pela fosforilação em tirosina do IRS-1 e a modulação negativa que acontece pela fosforilação em serina do mesmo IRS-1 (24,25). Está bem estabelecido que insulina e IGF-1 induzem a fosforilação em tirosina do IRS-1, enquanto agentes que sabidamente levam à resistência à insulina, tais como TNF- $\alpha$, ácidos graxos livres, estresse celular e hiperinsulinemia, induzem a ativação de quinases de serina/treonina que fosforilam o IRS-1 em serina, inibindo sua função (25). A fosforilação inibitória do IRS-1 em serina pode ser um mecanismo molecular unificador dos diversos fatores desencadeantes de resistência à insulina.

\section{EVENTOS MOLECULARES RELACIONADOS À INTERAÇÃO INSULINA X ANGIOTENSINA}

\section{A angiotensina e a via IRS-1/PI-3 quinase}

Vários estudos mostram que a angiotensina II, o principal peptídeo efetor do sistema renina-angiotensina, desempenha um papel fundamental no desenvolvimento tanto da hipertensão arterial quanto da resistência à insulina (7). Agentes que inibem a ação da angiotensina II, como, por exemplo, os inibidores da enzima de conversão da angiotensina e os bloqueadores do seu receptor ATl, levam à redução da pressão arterial e também a um aumento da sensibilidade à insulina em pacientes hipertensos previamente resistentes à insulina $(26,27)$.

Levando-se em consideração esses achados clínicos e a associação epidemiológica entre resistência à insulina, hipertensão e doença cardiovascular, vários estudos foram realizados para investigar a interação das etapas iniciais de sinalização desses dois hormônios. 
Estudos realizados in vivo e em cultura de células mostraram que, de forma similar à insulina, a angiotensina II é capaz de estimular a fosforilação em tirosina do IRS-1 e do IRS-2 (28-30). Estas fosforilações são induzidas rapidamente e são secundárias à ativação da JAK-2, membro da família das Janus kinases. A sinalização através da família JAK foi descrita inicialmente para receptores da família das citocinas, incluindo receptores de interleucinas e interferon, mas estudos subseqüentes mostraram que a cascata JAK/STAT pode ser ativada também por receptores associados à proteína $\mathrm{G}(15,31)$. De fato, estudos realizados in vivo e em cultura de células mostraram que a angiotensina II é capaz de induzir rapidamente a fosforilação em tirosina da JAK-2, ativando sua capacidade catalítica e induzindo sua associação e co-imunoprecipitação com IRS-1 e IRS-2 $(29,30)$. Este fenômeno acontece em paralelo com a fosforilação em tirosina, tanto do IRS-1 quanto do IRS-2 (29). Além disso, essa rápida fosforilação em tirosina da JAK2 e associação com IRS-1 e IRS-2 sugere a formação de um grande complexo de sinalização dessas proteínas com o receptor ATl após o estímulo com angiotensina II $(29,32)$.

Sempre que ocorre a fosforilação em tirosina de IRS- $1 / 2$, acontece a ligação dessas proteínas à subunidade regulatória p85 da PI-3 quinase. No entanto, de forma antagônica à observada após o estímulo insulínico, a atividade da PI-3 quinase associada à IRSl e IRS-2 encontra-se diminuída após o estímulo com angiotensina II de uma forma dose-dependente (29). Estudos realizados in vivo em músculo cardíaco de ratos mostraram que a angiotensina II é capaz de estimular a fosforilação em tirosina de IRS-1 e IRS-2 e suas respectivas associações com a PI-3 quinase, mas inibindo a atividade catalítica desta enzima $(28,29)$. Bloqueadores do receptor ATl são capazes de prevenir esse fenômeno (33). Concluindo, estudos realizados tanto in vivo quanto em cultura de células mostram que a angiotensina II é capaz de inibir a sinalização da insulina através da via da PI-3 quinase, possivelmente pela ativação de seu receptor ATl.

Tanto a redução da fosforilação em tirosina quanto o aumento da fosforilação em serina da subunidade $\beta$ do receptor de insulina, assim como do IRS$\mathrm{l}$, foram propostos como mecanismos moleculares de resistência à insulina $(25,30,34,35)$. Neste contexto, a angiotensina II é capaz de induzir a fosforilação em serina de três componentes da via de sinalização de insulina: o próprio receptor de insulina, IRS- 1 e a subunidade regulatória p85 da PI-3 quinase (30) (figura $3)$. Estudos em cultura de células de músculo liso de

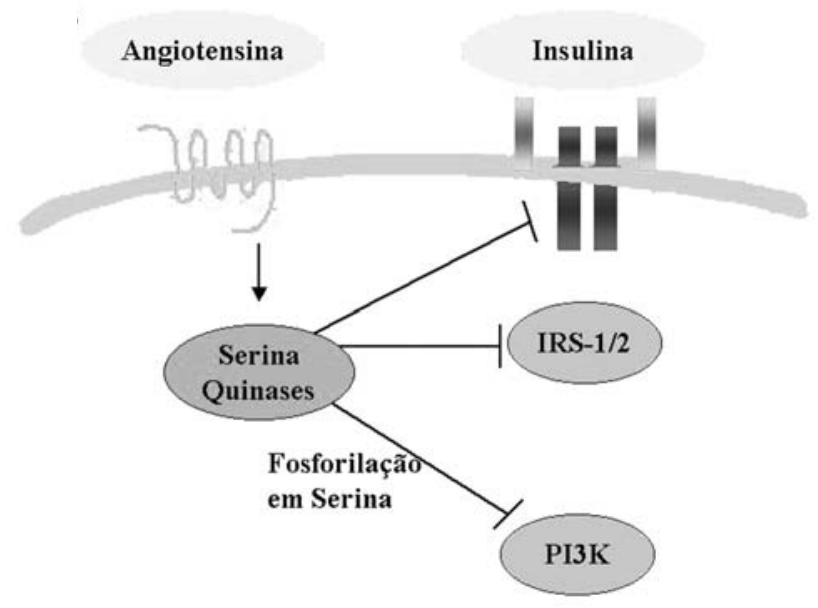

Figura 3. A angiotensina é capaz de ativar proteínas serina quinases e inibir a sinalização de insulina pela via IR//RS1/PI-3 quinase.

aorta de ratos mostraram que a angiotensina II induziu a fosforilação em serina tanto de IR quanto de IRS-1. Esta fosforilação em serina do IRS-1 diminuiu sua capacidade de associação à sub-unidade $\beta$ do receptor de insulina. Além disso, a utilização de inibidores de fosfatases de serina/treonina mimetizaram os efeitos da angiotensina II sobre IRS-1 e PI3 quinase (30). Recentemente, foi demonstrado que a angiotensina II é capaz de bloquear os efeitos vasodilatadores da insulina através da fosforilação em serina do IRS-1 nos resíduos Ser312 e Ser616, através da ativação das serina-quinase JNK e ERKl-2, o que leva à modulação negativa da via IRS-1/PI-3 quinase/Akt/ eNOS, diminuindo a produção de NO induzida por insulina (36).

\section{O PAPEL DA SOCS-3 NA INTERAÇÃO INSULINA X ANGIOTENSINA}

Como mostramos anteriormente, a ativação do receptor de angiotensina II ATl leva à ativação da via intracelular JAK/STAT. Esta via, além de ativar a transcrição de diversos efetores intracelulares diferentes, induz também a expressão de proteínas da família dos supressores de sinalização de citocina (SOCS), entre elas a SOCS-3, que tem efeito de feedback negativo sobre esta via, caracterizando possivelmente a mais duradoura forma de inibição da sinalização pela via JAK/STAT (37).

Tanto a insulina quanto a angiotensina II são capazes de induzir a expressão de proteínas da família SOCS em tecidos de animais in vivo e em culturas de células (38-42). Depois de induzido, SOCS-3 liga-se 
ao resíduo $\operatorname{Tyr}^{960}$ do receptor de insulina e diminui sua capacidade de fosforilar em tirosina o STAT-5b, o IRS-1 e o IRS-2 $(38,40,43)$. Além disso, a SOCS-3 é capaz de ligar-se ao IRS-1/2, provocando sua degradação proteossômica, através de um mecanismo dependente de ubiquitinação (44) (figura 4).

A interação da SOCS-3 induzida pela angiotensina II com as proteínas das vias de sinalização insulínica tem implicações moleculares e funcionais. No nível molecular, essa interação impede a fosforilação em tirosina de IRS-1 e IRS-2 e a fosforilação em serina e ativação da Akt (41). Além disso, a indução da SOCS-3 pela angiotensina II impede a ativação da via JAK-2/STAT5 b pela insulina (41). No nível funcional, o aumento da expressão de SOCS-3 induzido pela angiotensina II impede a translocação do GLUT4 intracelular para superfície da membrana de células do coração e de células cardíacas isoladas (41). Portanto, a SOCS-3 representa uma interface distal nos sistemas de sinalização de insulina e angiotensina II. Se, por um lado, isso pode representar uma proteção dos órgãos-alvo da insulina contra um estímulo constante de crescimento, por outro lado a indução da expressão da SOCS-3 pode impedir uma transmissão eficiente do sinal de insulina pela via metabólica, dificultando a aquisição de energia.

\section{O PAPEL DA MAP QUINASE NA INTERAÇÃO INSULINA X ANGIOTENSINA}

A ERKl/2 é outro ponto distal de interação das vias de sinalização da insulina e angiotensina II. O sinal insulínico pode ativar a ERKl $/ 2$ por dois mecanismos moleculares diferentes. A fosforilação e ativação do

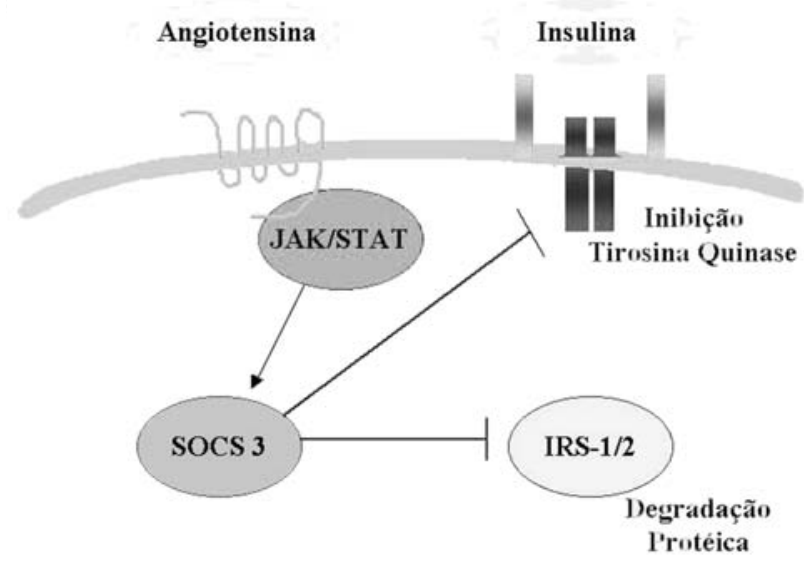

Figura 4. A angiotensina é capaz de induzir a expressão de SOCS3 e inibir a capacidade tirosina quinase do IR $\beta$, além de induzir a degradação protéica de IRS-1/2. receptor de insulina provocam sua interação e fosforilação em tirosina de uma proteína chamada Shc. Uma vez fosforilada, a Shc recruta outra proteína chamada Grb2 e induz a ativação da via Ras-Raf-MEK-ERK $(45,46)$. O receptor de insulina ativado também fosforila em tirosina os substratos IRS-1 e IRS-2, que podem interagir diretamente com a Grb2 e então ativar a via Ras-Raf-MEK-ERK (47).

A angiotensina II também pode ativar a ERKI/2 de duas formas distintas. A primeira é através da sua ligação com seu receptor $A T 1$, que ativa a proteína $\mathrm{G} q$, que leva ao aumento do conteúdo de $\mathrm{Ca}^{++}$citoplasmático e a subseqüente ativação do receptor de EGF. Uma vez ativado, o receptor de EGF recruta Shc/Grb2 e então ativa a via Ras-Raf-MEK-ERK $(48,49)$. O segundo mecanismo também depende da ativação da proteína $\mathrm{G} q$ pelo ATl e do aumento do conteúdo de $\mathrm{Ca}^{++}$citoplasmático, que provoca a ativação da $\mathrm{PKC}$ que ativa o Raf-1, que pode ativar a $\mathrm{MEK}$ e a $\mathrm{ERKl} / 2$, independentemente da ativação do Ras $(50,51)$.

Em células vasculares endoteliais, a insulina estimula a produção de NO através da ativação da via IRS1/PI-3 quinase/Akt, que leva à fosforilação e ativação da eNOS $(52,53)$. O pré-tratamento destas células com angiotensina II leva à ativação da ERK 1/2 e da Jnk por um mecanismo molecular dependente da ativação do ATl. Estas serina-quinases, uma vez ativadas, promovem a fosforilação em serina do IRS-1, impedindo a ativação da eNOS mediada pela insulina (36). Portanto, nesse tecido, a angiotensina II é capaz de induzir resistência à insulina pela via do IRS-1 por um mecanismo dependente de Jnk e ERK 1/2. Em concordância com este achado, o tratamento simultâneo de cobaias com insulina e angiotensina leva a um bloqueio da sinalização de insulina pela via IRS-1/PI-3 quinase/Akt, ao mesmo tempo em que leva a um aumento da sinalização pela via da ERK (32). Esse mecanismo está constitutivamente ativo num modelo animal de síndrome metabólica e parece ter um papel de destaque na hipertrofia do miocárdio relacionada à resistência à insulina (32).

\section{EFEITOS DOS INIBIDORES DA ENZIMA DE CONVERSÃO E DOS AUMENTOS DOS NIVVIS DE BRADICININA NAS AÇŌES METABÓLICAS E CELULARES DA INSULINA}

Na prática clínica, os efeitos benéficos da administração dos inibidores da enzima conversora e dos bloqueadores de ATl em pacientes com DM2 são conhecidos há bastante tempo (54-56). A hiper-atividade do sistema renina-angiotensina prejudica a sinalização intracelular da 
insulina e contribui para a resistência à insulina observada na hipertensão essencial (7). Essa hiper-atividade do sistema renina-angiotensina modula a sinalização de insulina diminuindo a captação muscular de glicose induzida por insulina $(56,57)$.

No nível molecular, o captopril melhora a sensibilidade à insulina através do aumento da fosforilação em tirosina do IRS-1 e de sua ligação e ativação da PI3 quinase, após o estímulo com insulina (33). Esses dados sugerem que a melhora da sensibilidade à insulina induzida pelo tratamento com captopril está relacionada à sua ação nas etapas inicias da transmissão do sinal de insulina, o que mostra a importância da interação entre insulina e angiotensina II.

Neste ponto da discussão é importante salientar que os efeitos da inibição da enzima de conversão vão além de somente diminuir a produção do potente vasoconstritor que é a angiotensina, mas também da diminuição da degradação do potente vasodilatador que é a bradicinina. De fato, a enzima de conversão tem mais afinidade pela bradicinina do que pela angiotensina I, e pode ser considerada mais uma cininase do que uma angiotensininase (58). Estudos anteriores mostram que a bradicinina pode melhorar a sensibilidade à insulina no tocante ao metabolismo da glicose (58), e alguns autores relacionam essa melhora à sua capacidade de melhorar o fluxo sangüíneo capilar, melhorando a distribuição de glicose e insulina para o tecido muscular (54).

A bradicinina provoca vasodilatação, pois induz a liberação de NO pelas células endoteliais e, como conseqüência, aumenta o transporte de glicose transcapilar (58). Além disso, no músculo esquelético e tecido adiposo, a bradicinina induz a translocação do transportador de glicose sensível à insulina GLUT 4 para a superfície celular (58), enquanto em células miocárdicas, além de aumentar a translocação de GLUT 4, a bradicinina induz a expressão de GLUT 1 (58). Ainda no músculo esquelético, a bradicinina é capaz de inibir certas fosfatases de tirosina que desfosforilam o IR e o IRS-1. Portanto, a bradicinina é responsável por alguns dos efeitos benéficos dos inibidores de enzima de conversão sobre a transmissão do sinal de insulina, já que é capaz de aumentar a fosforilação em tirosina tanto do IR quanto do IRS-1 (33).

\section{A ANGIOTENSINA INDUZ RESISTÊNCIA À INSULINA NO VASO E DISFUNÇĀO ENDOTELIAL}

Até aqui mostramos que a angiotensina II é capaz de modular negativamente a transmissão do sinal de insulina, bloqueando a via IRS/PI-3 quinase/Akt, e que os inibidores de enzima de conversão podem reverter esses efeitos em situações de resistência à insulina. Está estabelecido que esta mesma via é capaz de induzir a produção de $\mathrm{NO} e$, portanto, vasodilatação, em células endoteliais, onde a Akt, depois de ativada pela ação da PI-3 quinase, é capaz de fosforilar a eNOS e provocar sua ativação (5). Estes efeitos estimulatórios da insulina sobre a eNOS e a produção de NO podem ser importantes na prevenção da disfunção endotelial e das etapas iniciais da aterosclerose induzidas pelo LDL oxidado, pelo tabagismo e por outros fatores (5). A angiotensina II, tendo efeito inibitório sobre essa via de sinalização, pode diminuir a produção de NO ao mesmo tempo em que estimula a produção de radicais livres de oxigênio, aumentando o estresse oxidativo e aumentando a degradação do NO. Portanto, ao mesmo tempo em que a angiotensina II tem efeito deletério sobre o metabolismo da glicose mediado pela insulina em tecido muscular esquelético e cardíaco, pode também afetar a sinalização de insulina nos vasos sangüíneos, contribuindo para disfunção endotelial (5).

\section{OBESIDADE, RESISTÊNCIA À INSULINA E ANGIOTENSINA}

Diversos estudos clínicos mostram que o bloqueio do sistema renina-angiotensina, seja com inibidores de enzima conversora ou com bloqueadores do receptor de angiotensina II AT1, reduzem a incidência de DM2 em pacientes de alto risco. Uma meta-análise desses trabalhos, envolvendo dados de mais de 33.100 pacientes, mostrou uma redução na incidência de DM2 de 22\% ( $<<0,0001)$ quando comparada com outros regimes anti-hipertensivos (59).

Recentemente, um grande estudo clínico foi realizado para investigar a capacidade do inibidor de enzima conversora ramipril em diminuir a incidência de DM2 em indivíduos com intolerância à glicose de jejum ou após sobrecarga oral de glicose (60). Apesar do uso do ramipril estar associado a uma maior normalização da glicemia, não houve diminuição significativa da incidência de DM2 quando comparada com o grupo controle (60). Este achado pode, inicialmente, não parecer compatível com os achados clínicos e moleculares anteriores, da ação da angiotensina II sobre o metabolismo de glicose. Essa aparente discrepância pode ter sua explicação baseada na escolha dos pacientes para este estudo, particularmente no fato de estes indivíduos apresentarem um menor risco cardiovascular do que os pacientes em 
que o benefício do uso de inibidores de enzima conversora fora demonstrado anteriormente.

Um estudo clínico recente mostrou um aumento da ativação do sistema renina-angiotensina em pacientes obesos. Mulheres obesas, quando comparadas com mulheres não-obesas, mostraram níveis plasmáticos elevados de enzima conversora, angiotensinogênio, renina e aldosterona, e aumento da expressão gênica de angiotensinogênio no tecido adiposo $(\mathrm{p}<$ $0,05)$. Uma perda média de $5 \mathrm{~kg}$ no grupo de mulheres obesas, que foi associada à diminuição da circunferência abdominal, provocou diminuições significativas na ativação do sistema renina-angiotensina, refletida pelas quedas nas concentrações plasmáticas dos mediadores citados (61).

A obesidade está relacionada à hipertrofia do tecido adiposo, que é um órgão endócrino ativo e secreta diversos hormônios que podem levar ao desenvolvimento de resistência à insulina, entre eles a angiotensina II e outras citocinas (62). Recentemente demonstrou-se que o angiotensinogênio secretado pelo tecido adiposo possui papel importante no desenvolvimento do próprio tecido adiposo, assim como na hipertensão arterial associada à obesidade (63).

Ambos os receptores de angiotensina II, ATl e AT2, estão expressos no tecido adiposo. O uso de valsartan aumentou a captação de glicose induzida por insulina no tecido adiposo, enquanto o camundongo com deleção do gene codificador do receptor AT2 mostra captação de glicose reduzida (64). Estes achados sugerem uma ação antagônica entre ATl e AT2 em relação à captação de glicose induzida por insulina.

Mas talvez o papel mais intrigante da angiotensina sobre o tecido adiposo esteja associado a seus efeitos na adipogênese. Em camundongos com deleção específica do receptor de angiotensina II AT2, observamos uma massa adiposa similar ao controle, porém caracterizada por adipócitos menores e em maior número. Este animal mostrou uma maior capacidade de oxidação de lipídeos, e mostrou-se protegido das ações deletérias de uma dieta rica em lipídeos, tanto em relação ao desenvolvimento de obesidade quanto de resistência à insulina (65). Estes dados sugerem que a sinalização de angiotensina II via seu receptor AT2 promove um aumento da massa adiposa e leva à intolerância à glicose.

De forma semelhante, o camundongo com deleção para o receptor de angiotensina II ATl também apresenta proteção aos efeitos deletérios da dieta hiperlipídica, tanto em relação ao ganho de peso quanto ao desenvolvimento de resistência à insulina, sugerindo também um papel do ATl no ganho de peso e resistência à insulina observados na obesidade (66).
Estes dados sugerem um papel da angiotensina II na adipogênese, e também como uma das substâncias produzidas pelo tecido adiposo hipertrófico, que podem modular de forma negativa a sensibilidade à insulina, podendo ser um possível elo entre obesidade, resistência à insulina, DM2 e hipertensão arterial.

\section{PODE A INSULINA MODULAR A AÇÃO DA ANGIOTENSINA?}

Como apresentado nas seções anteriores, as ações da angiotensina II sobre a via de sinalização insulínica foram intensamente investigadas em diversos modelos experimentais diferentes, mas o reverso não é verdadeiro. A capacidade da insulina (ou da hiperinsulinemia) em modular a produção ou atividade intracelular da angiotensina II foi pouco estudada. Três estudos diferentes investigaram este problema e têm resultados semelhantes. Nickenig e cols. (67) observaram que o tratamento agudo com insulina aumenta de forma significativa a expressão de receptores ATl em células musculares lisas da vasculatura. De forma semelhante, Banday e cols. (68) observaram um aumento da expressão celular de ATl e um aumento da atividade da angiotensina II sobre a Na-KATPase e canais de $\mathrm{Na} / \mathrm{H}$ em células renais. E, finalmente, Golovchanko e cols. (69) demonstraram que a hiperinsulinemia aumenta a capacidade de a angiotensina II ativar a transcrição protéica induzida por $\mathrm{NFKB}$ em células musculares lisas da vasculatura. Apesar do pequeno número de estudos neste campo, acreditamos que exista sim uma regulação da sinalização intracelular da angiotensina pela insulina, em diferentes tecidos e linhagens celulares, mas que, ao contrário dos efeitos da angiotensina II sobre a ação insulínica, essa regulação seja estimulatória.

\section{CONCLUSÃO}

A interação entre os diversos mecanismos de sinalização intracelular é um pré-requisito fundamental para uma adaptação evolutiva bem sucedida. Hoje sabemos que os sistemas de sinalização de insulina e angiotensina II compartilham diversas proteínas intracelulares, e que um hormônio pode modular as funções do outro. Até o momento as razões evolutivas desta interação tão complexa e elaborada não estão claras. No entanto, sabemos que em organismos vivos complexos, a integração entre os sistemas circulatório e metabólico é de fundamental importância para o controle de 
diversas funções fisiológicas, como a distribuição dos nutrientes, o controle da temperatura corporal, a manutenção do equilíbrio de sal e água, entre outras. A insulina e a angiotensina II desempenham papel fundamental no controle metabólico e cardiocirculatório, respectivamente. A disfunção desses dois hormônios, em graus variados, pode levar a duas condições patológicas de alta prevalência e que muitas vezes são concomitantes: diabetes mellitus e hipertensão arterial. Se, por um lado, a interação entre estas duas vias de sinalização parece contribuir para a associação clínica entre DM2 e hipertensão arterial, por outro lado a caracterização molecular dessa interação poderá revelar alvos para futuras intervenções terapêuticas para essas duas condições clínicas.

\section{REFERÊNCIAS}

1. Pessin JE, Saltiel AR. Signaling pathways in insulin action: molecular targets of insulin resistance. J Clin Invest 2000;106:165-9.

2. Kahn BB, Flier JS. Obesity and insulin resistance. J Clin Invest 2000;106:473-81.

3. Olefsky JM, Saltiel AR. PPAR gamma and the treatment of insulin resistance. Trends Endocrinol Metab 2000;11:362-8.

4. Reaven G. The metabolic syndrome or the insulin resistance syndrome? Different names, different concepts, and different goals. Endocrinol Metab Clin North Am 2004;33:283303.

5. Wang CC, Goalstone ML, Draznin B. Molecular mechanisms of insulin resistance that impact cardiovascular biology. Diabetes 2004;53:2735-40.

6. Reaven G, Abbasi F, McLaughlin T. Obesity, insulin resistance, and cardiovascular disease. Recent Prog Horm Res 2004;59:207-23.

7. Natali A, Ferrannini E. Hypertension, insulin resistance, and the metabolic syndrome. Endocrinol Metab Clin North Am 2004;33:417-29.

8. Shulman GI. Cellular mechanisms of insulin resistance in humans. Am J Cardiol 1999;84:3J-10J.

9. Saltiel $A R$, Kahn CR. Insulin signalling and the regulation of glucose and lipid metabolism. Nature 2001;414:799-806.

10. Van Gaal LF, Mertens IL, De Block CE. Mechanisms linking obesity with cardiovascular disease. Nature 2006;444:875-80.

11. Griendling KK, Lassegue B, Murphy TJ, Alexander RW. Angiotensin II receptor pharmacology. Adv Pharmacol 1994;28:269-306.

12. Shirai H, Takahashi K, Katada T, Inagami T. Mapping of G protein coupling sites of the angiotensin II type 1 receptor. Hypertension 1995;25:726-30.

13. Bernstein KE, Ali MS, Sayeski PP, Semeniuk D, Marrero MB. New insights into the cellular signaling of seven transmembrane receptors: the role of tyrosine phosphorylation. Lab Invest 1998;78:3-7

14. Sadoshima J. Versatility of the angiotensin II type 1 receptor. Circ Res 1998;82:1352-5.

15. Venema RC, Venema VJ, Eaton DC, Marrero MB. Angiotensin II-induced tyrosine phosphorylation of signal transducers and activators of transcription 1 is regulated by Janus-activated kinase 2 and Fyn kinases and mitogen-activated protein kinase phosphatase 1. J Biol Chem 1998;273:30795-800.

16. Mukoyama M, Nakajima M, Horiuchi $M$, Sasamura $H$, Pratt RE, Dzau VJ. Expression cloning of type 2 angiotensin II receptor reveals a unique class of seven-transmembrane receptors. J Biol Chem 1993;268:24539-42.
17. Stoll M, Unger T. Angiotensin and its AT2 receptor: new insights into an old system. Regul Pept 2001;99:175-82.

18. Carey RM. Cardiovascular and renal regulation by the angiotensin type 2 receptor: the AT2 receptor comes of age. Hypertension 2005;45:840-4.

19. Huang XC, Richards EM, Sumners C. Mitogen-activated protein kinases in rat brain neuronal cultures are activated by angiotensin II type 1 receptors and inhibited by angiotensin II type 2 receptors. J Biol Chem 1996;271:15635-41.

20. Zhu M, Gelband CH, Moore JM, Posner P, Sumners C. Angiotensin II type 2 receptor stimulation of neuronal delayed-rectifier potassium current involves phospholipase A2 and arachidonic acid. J Neurosci 1998;18:679-86.

21. Saad MJ, Carvalho CR, Thirone AC, Velloso LA. Insulin induces tyrosine phosphorylation of JAK2 in insulin-sensitive tissues of the intact rat. J Biol Chem 1996;271:22100-4.

22. Velloso LA, Carvalho CR, Rojas FA, Folli F, Saad MJ. Insulin signalling in heart involves insulin receptor substrates-1 and -2 , activation of phosphatidylinositol 3-kinase and the JAK 2growth related pathway. Cardiovasc Res 1998;40:96-102.

23. Araujo EP, De Souza CT, Gasparetti AL, Ueno M, Boschero $A C$, Saad MJ, et al. Short-term in vivo inhibition of insulin receptor substrate-1 expression leads to insulin resistance, hyperinsulinemia, and increased adiposity. Endocrinology 2005;146:1428-37.

24. Hotamisligil GS, Peraldi P, Budavari A, Ellis R, White MF, Spiegelman BM. IRS-1-mediated inhibition of insulin receptor tyrosine kinase activity in TNF-alpha- and obesity-induced insulin resistance. Science 1996;271:665-8.

25. Sykiotis GP, Papavassiliou AG. Serine phosphorylation of insulin receptor substrate-1: a novel target for the reversal of insulin resistance. Mol Endocrinol 2001;15:1864-9.

26. Feldman R. ACE inhibitors versus AT1 blockers in the treatment of hypertension and syndrome $\mathrm{X}$. Can J Cardiol 2000;16(Suppl E):41E-44E.

27. Scheen AJ. Prevention of type 2 diabetes mellitus through inhibition of the Renin-Angiotensin system. Drugs 2004;64:2537-65.

28. Saad MJ, Velloso LA, Carvalho CR. Angiotensin II induces tyrosine phosphorylation of insulin receptor substrate 1 and its association with phosphatidylinositol 3-kinase in rat heart. Biochem J 1995;310(Pt 3):741-4.

29. Velloso LA, Folli F, Sun XJ, White MF, Saad MJ, Kahn CR. Cross-talk between the insulin and angiotensin signaling systems. Proc Natl Acad Sci USA 1996;93:12490-5.

30. Folli $F$, Kahn CR, Hansen H, Bouchie JL, Feener EP. Angiotensin II inhibits insulin signaling in aortic smooth muscle cells at multiple levels. A potential role for serine phosphorylation in insulin/angiotensin II crosstalk. J Clin Invest 1997; 100:2158-69.

31. Marrero MB, Schieffer B, Paxton WG, Heerdt L, Berk BC, Delafontaine $\mathrm{P}$, et al. Direct stimulation of Jak/STAT pathway by the angiotensin II AT1 receptor. Nature 1995;375:247-50.

32. Carvalheira JB, Calegari VC, Zecchin HG, Nadruz W, Jr., Guimarães RB, Ribeiro EB, et al. The cross-talk between angiotensin and insulin differentially affects phosphatidylinositol 3-kinase- and mitogen-activated protein kinase-mediated signaling in rat heart: implications for insulin resistance. Endocrinology 2003;144:5604-14.

33. Carvalho CR, Thirone AC, Gontijo JA, Velloso LA, Saad MJ. Effect of captopril, losartan, and bradykinin on early steps of insulin action. Diabetes 1997;46:1950-7.

34. Tanti JF, Gremeaux T, van Obberghen E, Le Marchand-Brustel Y. Serine/threonine phosphorylation of insulin receptor substrate 1 modulates insulin receptor signaling. J Biol Chem 1994:269:6051-7.

35. Mothe I, Van Obberghen E. Phosphorylation of insulin receptor substrate-1 on multiple serine residues, $612,632,662$, and 731 , modulates insulin action. J Biol Chem 1996;271:11222-7.

36. Andreozzi F, Laratta E, Sciacqua A, Perticone F, Sesti G. Angiotensin II impairs the insulin signaling pathway promoting production of nitric oxide by inducing phosphorylation of insulin receptor substrate-1 on Ser312 and Ser616 in human umbilical vein endothelial cells. Circ Res 2004;94:1211-8. 
37. Krebs DL, Hilton DJ. SOCS: physiological suppressors of cytokine signaling. J Cell Sci 2000;113(Pt 16):2813-9.

38. Emanuelli B, Peraldi P, Filloux C, Sawka-Verhelle D, Hilton D, Van Obberghen E. SOCS-3 is an insulin-induced negative regulator of insulin signaling. J Biol Chem 2000;275:15985-91.

39. Sadowski CL, Choi TS, Le M, Wheeler TT, Wang LH, Sadowski HB. Insulin induction of SOCS-2 and SOCS-3 mRNA expression in $\mathrm{C} 2 \mathrm{C} 12$ skeletal muscle cells is mediated by Stat5*. J Biol Chem 2001;276:20703-10.

40. Emanuelli B, Peraldi P, Filloux C, Chavey C, Freidinger K, Hilton DJ, et al. SOCS-3 inhibits insulin signaling and is up-regulated in response to tumor necrosis factor-alpha in the adipose tissue of obese mice. J Biol Chem 2001;276:47944-9.

41. Calegari VC, Bezerra RM, Torsoni MA, Torsoni AS, Franchini $\mathrm{KG}$, Saad MJ, et al. Suppressor of cytokine signaling 3 is induced by angiotensin II in heart and isolated cardiomyocytes, and participates in desensitization. Endocrinology 2003; $144: 4586-96$

42. Torsoni MA, Carvalheira JB, Calegari VC, Bezerra RM, Saad MJ, Gontijo JA, et al. Angiotensin II (Angll) induces the expression of suppressor of cytokine signaling (SOCS)-3 in rat hypothalamus - a mechanism for desensitization of Angll signaling. J Endocrinol 2004;181:117-28.

43. Ueki K, Kondo T, Kahn CR. Suppressor of cytokine signaling 1 (SOCS-1) and SOCS-3 cause insulin resistance through inhibition of tyrosine phosphorylation of insulin receptor substrate proteins by discrete mechanisms. Mol Cell Biol 2004; $24: 5434-46$.

44. Rui L, Yuan M, Frantz D, Shoelson S, White MF. SOCS-1 and SOCS-3 block insulin signaling by ubiquitin-mediated degradation of IRS1 and IRS2. J Biol Chem 2002:277:42394-8.

45. Giorgetti S, Pelicci PG, Pelicci G, Van Obberghen E. Involvement of Src-homology/collagen (SHC) proteins in signaling through the insulin receptor and the insulin-like-growth-factor-I-receptor. Eur J Biochem 1994;223:195-202.

46. Holt KH, Kasson BG, Pessin JE. Insulin stimulation of a MEKdependent but ERK-independent SOS protein kinase. Mol Cell Biol 1996;16:577-83.

47. Sarbassov DD, Peterson CA. Insulin receptor substrate-1 and phosphatidylinositol 3-kinase regulate extracellular signalregulated kinase-dependent and -independent signaling pathways during myogenic differentiation. Mol Endocrinol 1998; 12:1870-8.

48. Eguchi S, Iwasaki $H$, Ueno H, Frank GD, Motley ED, Eguchi K, et al. Intracellular signaling of angiotensin II-induced p70 S6 kinase phosphorylation at Ser(411) in vascular smooth muscle cells. Possible requirement of epidermal growth factor receptor, Ras, extracellular signal-regulated kinase, and Akt. J Biol Chem 1999;274:36843-51.

49. Werry TD, Sexton PM, Christopoulos A. "Ins and outs" of seven-transmembrane receptor signalling to ERK. Trends Endocrinol Metab 2005;16:26-33.

50. Hunyady L, Turu G. The role of the AT1 angiotensin receptor in cardiac hypertrophy: angiotensin II receptor or stretch sensor? Trends Endocrinol Metab 2004;15:405-8.

51. Zou Y, Komuro I, Yamazaki T, Aikawa R, Kudoh S, Shiojima I, et al. Protein kinase C, but not tyrosine kinases or Ras, plays a critical role in angiotensin II-induced activation of Raf-1 kinase and extracellular signal-regulated protein kinases in cardiac myocytes. J Biol Chem 1996;271:33592-7.

52. Zeng G, Nystrom FH, Ravichandran LV, Cong LN, Kirby M, Mostowski $\mathrm{H}$, et al. Roles for insulin receptor, PI3-kinase, and Akt in insulin-signaling pathways related to production of nitric oxide in human vascular endothelial cells. Circulation 2000;101:1539-45.

53. Zecchin HG, Bezerra RM, Carvalheira JB, Carvalho-Filho MA, Metze K, Franchini KG, et al. Insulin signalling pathways in aorta and muscle from two animal models of insulin resistance-the obese middle-aged and the spontaneously hypertensive rats. Diabetologia 2003;46:479-91.
54. Jauch KW, Hartl W, Guenther B, Wicklmayr M, Rett K, Dietze G. Captopril enhances insulin responsiveness of forearm muscle tissue in non-insulin-dependent diabetes mellitus. Eur J Clin Invest 1987:17:448-54.

55. Moan A, Risanger T, Eide I, Kjeldsen SE. The effect of angiotensin II receptor blockade on insulin sensitivity and sympathetic nervous system activity in primary hypertension. Blood Press 1994;3:185-8.

56. Kurtz TW, Pravenec M. Antidiabetic mechanisms of angiotensin-converting enzyme inhibitors and angiotensin II receptor antagonists: beyond the renin-angiotensin system. $\mathbf{J}$ Hypertens 2004;22:2253-61.

57. Fukuda N, Satoh C, Hu WY, Nakayama M, Kishioka H, Kanmatsuse K. Endogenous angiotensin II suppresses insulin signaling in vascular smooth muscle cells from spontaneously hypertensive rats. J Hypertens 2001;19:1651-8.

58. Damas J, Garbacki N, Lefebvre PJ. The kallikrein-kinin system, angiotensin converting enzyme inhibitors and insulin sensitivity. Diabetes Metab Res Rev 2004;20:288-97.

59. Scheen AJ. VALUE: analysis of results. Lancet 2004;364:932-3; author reply 935.

60. Bosch J, Yusuf S, Gerstein HC, Pogue J, Sheridan P, Dagenais $\mathrm{G}$, et al. Effect of ramipril on the incidence of diabetes. $\mathbf{N}$ Engl J Med 2006;355:1551-62.

61. Engeli S, Bohnke J, Gorzelniak K, Janke J, Schling P, Bader $M$, et al. Weight loss and the renin-angiotensin-aldosterone system. Hypertension 2005;45:356-62.

62. Knowler WC, Barrett-Connor E, Fowler SE, Hamman RF, Lachin JM, Walker EA, et al. Reduction in the incidence of type 2 diabetes with lifestyle intervention or metformin. $\mathbf{N}$ Engl J Med 2002;346:393-403.

63. Massiera F, Bloch-Faure M, Ceiler D, Murakami K, Fukamizu A, Gasc JM, et al. Adipose angiotensinogen is involved in adipose tissue growth and blood pressure regulation. Faseb $\mathbf{J}$ 2001; 15:2727-9.

64. Shiuchi T, Iwai M, Li HS, Wu L, Min LJ, Li JM, et al. Angiotensin II type-1 receptor blocker valsartan enhances insulin sensitivity in skeletal muscles of diabetic mice. Hypertension 2004:43:1003-10.

65. Yvan-Charvet L, Even P, Bloch-Faure M, Guerre-Millo M, Moustaid-Moussa N, Ferre $P$, et al. Deletion of the angiotensin type 2 receptor (AT2R) reduces adipose cell size and protects from diet-induced obesity and insulin resistance. Diabetes 2005;54:991-9.

66. Kouyama R, Suganami T, Nishida J, Tanaka M, Toyoda T, Kiso $M$, et al. Attenuation of diet-induced weight gain and adiposity through increased energy expenditure in mice lacking angiotensin II type 1a receptor. Endocrinology 2005;146:3481-9.

67. Nickenig G, Roling J, Strehlow K, Schnabel P, Bohm M. Insulin induces upregulation of vascular AT1 receptor gene expression by posttranscriptional mechanisms. Circulation 1998;98:2453-60.

68. Banday AA, Siddiqui AH, Menezes MM, Hussain T. Insulin treatment enhances AT1 receptor function in OK cells. Am J Physiol Renal Physiol 2005;288:F1213-9.

69. Golovchenko I, Goalstone ML, Watson P, Brownlee M, Draznin B. Hyperinsulinemia enhances transcriptional activity of nuclear factor-kappaB induced by angiotensin II, hyperglycemia, and advanced glycosylation end products in vascular smooth muscle cells. Circ Res 2000;87:746-52.

\section{Endereço para correspondência:}

Mário José Abdalla Saad

Departamento de Clínica Médica

Faculdade de Ciências Médicas

Universidade Estadual de Campinas

E-mail: msaad@fcm.unicamp.br 